\title{
La cirugía mexicana en la primera mitad del siglo XX
}

\section{Mexican surgery in $20^{\text {th }}$ century}

\author{
Rolando Neri-Vela ${ }^{*}$, Luis A. Bonilla-Arcaute ${ }^{2}$ y Luis V. Sánchez-Fernández ${ }^{3}$
}

${ }^{1}$ Escuela Médico Naval, Universidad Naval, Secretaría de Marina-Armada de México, Ciudad de México, México; ${ }^{2}$ Dirección General de Sanidad

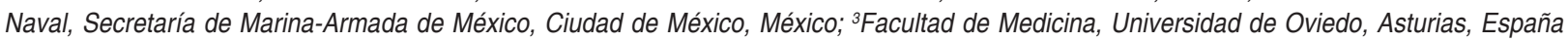

\section{Resumen}

Se hace un recuerdo de los principales cirujanos que han hecho que la cirugía en México haya alcanzado niveles de excelencia, que trabajaron principalmente en la primera mitad del siglo XX (aunque algunos de ellos se salgan de este periodo), las especialidades quirúrgicas en que destacaron, así como en qué instituciones trabajaron, y algunas de las técnicas quirúrgicas preconizadas por ellos. Se mencionan algunos grandes médicos que fueron sus alumnos.

Palabras Clave: Cirugía. México. Siglo XX.

\begin{abstract}
It is a remembrance about the main surgeons who have made that surgery have reached levels of excellence in Mexico, which worked mainly during the $1^{\text {st }}$ half of the $20^{\text {th }}$ century, although some of them are out of this period, the surgical specialties in which they stood out, as well as in which institutions they worked, and some of the surgical techniques recommended by them. Some great doctors who were their students are mentioned.
\end{abstract}

Key Words: Surgery. Mexico. 20 th century.

\section{Correspondencia:}

*Rolando Neri-Vela

Tuxpan, 16-401 


\section{Introducción}

A partir del inicio de las actividades de la Academia Mexicana de Cirugía, en 1933, el quehacer quirúrgico ha tenido un desenvolvimiento continuo.

Los adelantos en la cirugía mexicana han sido muchísimos, y no todos han tenido el mismo realce o la misma difusión, por lo que se puede pecar en la omisión de datos, principalmente al no citar a muchas personas que han tenido incumbencia en el área.

Así, se citarán en este ensayo diversos médicos, hospitales, revistas y trabajos que han influido en la modernización de la cirugía mexicana, y en ocasiones se repetirán algunos datos, pero necesarios. Asimismo, se mencionan personas que, aunque llevaron a cabo su labor principalmente en la segunda mitad del siglo XX, su vida se enlaza con las décadas precedentes. El tiempo y el espacio no permiten extenderse para profundizar en el tema, por lo que pedimos disculpas por las ausencias que hay en este trabajo.

\section{Primeros cirujanos}

En la primera mitad del siglo XX destacaron cirujanos de la talla de Rafael Vargas Otero en el Hospital Juárez y Darío Fernández Fierro, junto con sus discípulos Julián González Méndez y José García Noriega, a quienes correspondió la transformación científica de la cirugía, en el Hospital General. A Vargas Otero se debió la creación de la cátedra de práctica de la cirugía en perros y la iniciación a la cirugía torácica con intubación y respiración controlada.

También destacaron Abraham Ayala González, que formó su propia escuela, y Clemente Robles.

En el Instituto Mexicano del Seguro Social, fundado en 1943, las primeras operaciones se efectuaron en el sanatorio situado en avenida México y Michoacán, en la colonia Condesa de la Ciudad de México, comprado por dicha institución a Javier Rojo de la Vega'

Una de las grandes personalidades de la cirugía mexicana del siglo XX es Darío Fernández Fierro, quien en 1939 publicó sus técnicas de neurotomía retrogasseriana; consideraba injusto aceptar que los pacientes con neuralgia del trigémino fueran incurables. A diferencia de la técnica extradural propuesta por Spiller, Darío Fernández propuso la vía intradural a través de una craneotomía occipital combinada con una trepanación temporal que permitía acceder al ganglio de Gasser.
Otro de los grandes intereses de Darío Fernández fue la cirugía de tiroides, llevando a cabo centenares de tiroidectomías totales y subtotales, modificando y sistematizando las técnicas existentes para lograr una buena exposición de la glándula con control de las hemorragias y evitando las lesiones del nervio recurrente. Asimismo, en 1943 publicó una técnica para la corrección de la parálisis de las cuerdas vocales resultante de la cirugía tiroidea.

En 1937 publicó su técnica para la alcoholización del nervio frénico a cielo cerrado para lograr la parálisis diafragmática, que se empleaba para colapsar cavernas tuberculosas. También desarrolló una técnica de toracoplastía por vía axilar, que publicó con Mario Vergara Soto en 1946.

En 1945, en Costa Rica, Fernández Fierro presentó sus procedimientos de reconstrucción esofágica. Dentro de sus intereses estuvo la cirugía abdominal, y publicó su técnica de gastrectomía y gastroptosis. Desarrolló y modificó las técnicas de anestesia raquídea para encontrar aplicaciones nunca antes usadas en cirugía torácica y de cuello. Después de su muerte, sus discípulos José García Noriega y Mario Vergara Soto, con la ayuda editorial de Mario Hidalgo, publicaron en 1949 una recopilación de sus trabajos bajo el nombre de Testamento quirúrgico del doctor Darío Fernández Fierro².

\section{La neurocirugía}

Otro de los pilares de la cirugía mexicana moderna fue, sin duda alguna, Clemente Robles, quien organizó el primer servicio de neurocirugía que mereciera este nombre, sabiendo aprovechar el conocimiento de otros especialistas. En el pabellón 7 del Hospital General de México formó un grupo multidisciplinario con neurólogos, psiquiatras, oftalmólogos, radiólogos y electroencefalografistas.

Personalidades como las de Samuel Ramírez Moreno, Manuel Guevara Oropeza, Leopoldo Salazar Viniegra, Raúl González Enríquez, Guillermo Dávila, Alfonso Millán y Mario Fuentes Delgado fueron la base para el progreso de la neurocirugía mexicana.

Ramírez Moreno introdujo en México la neumoencefalografía y la electroencefalografía (que Teodoro Flores Covarrubias, ayudante de su clínica, hizo posible desde 1936 con un electroencefalógrafo construido por él mismo).

Se debe a Ramírez Moreno, Mario Fuentes y Gamboa Acosta, del Hospital General, a Dionisio Nieto, de La Castañeda, y a Marín Ramos Contreras y Pico 
Navarro, del Hospital Central Militar, el mayor apoyo para sustentar la cirugía neurológica como terapéutica definitiva en algunos padecimientos.

Al finalizar la década de 1930 surgió la necesidad de formar especialistas en cirugía neurológica, buscando el apoyo de maestros como Gustavo Baz Prada, José Aguilar Álvarez, Darío Fernández, Conrado Zuckerman, Salvador Uribe, Felipe Aceves Zubieta, Miguel Lavalle, Joaquín Maas, Mariano Vázquez y Clemente Robles.

En 1934, Miguel Lavalle operó con gran éxito, en el Hospital Juárez, ayudado por el practicante numerario Arseny Lepiavka, un meningocele occipital, junto con un pequeño encefalocele, en un niño de 2 semanas de edad, por primera vez en México y muy probablemente en América ${ }^{3}$.

De 1941 a 1944, varios médicos mexicanos, ya iniciados en la neurocirugía, lograron estar en el extranjero afinando sus conocimientos, entre ellos Manuel Velasco Suárez, Juan Cárdenas, Manuel Sánchez Garibay, Hernando Guzmán West, Ramón del Cueto, Eutimio Calzado, Luis Sáenz Arroyo, Gregorio González Mariscal y Miguel Ramos Murguía; más tarde se integraron a los principales servicios de neurocirugía médicos como Daniel González y Fernando Rueda Franco, Cristina García Sancho y Jorge Álvarez Loyo.

La especialidad se enriqueció con neurólogos de la talla de J. Hernández Peniche, Juvencio Robles, Carrasco Zannini, Ladislao Olivares, Francisco Rubio Donnadieu y Luis Lombardo, y con neuropatólogos como Juan Olvera, Joaquín Cravioto, Alfonso Escobar Izquierdo y Alfonso Reyes Contreras.

Al Hospital General de México se agregó Patricio Beltrán Goñi, dándole realce al servicio de neurología y neurocirugía de esta institución.

Otros cirujanos destacados han sido Horacio Martínez Romero, José María Sánchez Cabrera, Francisco Escobedo Ríos, José Humberto Mateos Gómez, Jesús López Lira, Sergio Gómez Llata, Carlos Sol Durán, Jesús Aguilar Rodríguez, Jaime Heyser, Octavio Quesnel, Carlos Castañeda Tamborrel y C. García Guerra, que han colaborado en la erección de la neurocirugía en los diferentes hospitales, tanto en la capital del país como en el interior de la República.

La angiografía cerebral con carótida expuesta se realizó por primera vez en México en el departamento de rayos $X$ del Hospital Juárez por neurocirujanos del mismo nosocomio, encabezados por Manuel Velasco Suárez.

El manejo de la hidrocefalia congénita con resección endoscópica de los plexos coroideos, derivación del líquido cefalorraquídeo al uréter y luego subaracnoidoperitoneales o al espacio suprahepático, realizado también en el Hospital Juárez, precedió a las derivaciones ventriculoatriales 0 peritoneales de Pudenz.

La psicocirugía selectiva fue introducida en México por Velasco Suárez y su equipo, en 1945, y después de la comunicación quirúrgica de Rojo de la Vega, en el Hospital General de México se introdujo la aplicación del praziquantel oral por M. Chavarría Chavarría y Clemente Robles, útil en las formas parenquimatosas.

El Instituto Nacional de Neurología y Neurocirugía, fundado por Manuel Velasco Suárez, ha dado fama mundial a la neurocirugía mexicana, como también lo han hecho infinidad de instituciones hospitalarias y de investigación nacionales en sus respectivas especialidades ${ }^{4}$.

\section{Cirugía cardiovascular y nefrológica}

Cuando en 1943 se fundó el Hospital Infantil de México, Clemente Robles fue llamado para encabezar su departamento de neurocirugía, y lo mismo ocurrió en el Hospital de las Enfermedades de la Nutrición, en 1947, en donde se tenía la idea de realizar poca cirugía, pero de alto nivel, y Robles tenía el conocimiento para ejecutar las operaciones del aparato digestivo, endocrinología y hematología que ahí se efectuarían. Se inició así la cirugía porto-cava, que al principio exigía un gran gasto de energía de cirujanos, anestesiólogos, internistas, transfusores, laboratoristas, etc.

En el Instituto Nacional de Cardiología, Robles se enfrentó al reto de problemas nuevos, para lo cual debió acoplarse con los internistas, formar técnicos en novedosos estudios de gabinete, de hemodinamia, cateterismo, determinación de gases en sangre, aprender a manejar la bomba de circulación extracorpórea, respiradores, monitores e inclusive crear salas especiales de cuidados intensivos con médicos, técnicos y enfermeras especializadas para hacer eficaz el equipo quirúrgico ${ }^{5}$.

Fernando Quijano Pitman, gran estudioso de la medicina en San Luis Potosí, nos ha dejado muchísimos datos de interés histórico-médico. Así, en San Luis Potosí, en 1948, Clemente Robles operó el primer caso de ductus arteriosus que se realizó fuera de la Ciudad de México.

La cirugía del corazón abierto fue iniciada en México por Raúl Baz Iglesias, quien en 1956 operó el primer caso utilizando la hipotermia de superficie. Al 
año siguiente, el mismo Baz usó la circulación extracorpórea con ayuda del corazón-pulmón artificial.

Gilberto Flores Izquierdo fue el introductor y el que usó por primera vez en México las sondas de Fogarty, revolucionando la cirugía arterial. También inició la cirugía de trasplantes venosos, sobre todo en el tratamiento del síndrome posflebítico, e introdujo el empleo de isótopos en el estudio de la circulación de los miembros.

La primera embolectomía que se hizo en México de la arteria mesentérica superior fue hecha por Arturo Aguillón en 1962, en un enfermo convaleciente de comisurotomía mitral, con la estrecha colaboración de José Miguel Torre y Ricardo Quilantán.

Alberto Alcocer Andalón, en 1960, inició en México el tratamiento de la trombosis iliofemoral mediante trombectomía venosa, y fue el primero en México en hacer valvuloplastías venosas en casos de várices.

Manuel Quijano Narezo fue pionero en los trasplantes de riñón, junto con Federico Ortiz Quesada, en el Centro Médico Nacional, del Instituto Mexicano del Seguro Social. A Quijano Narezo se debe también el inicio de la cirugía pancreática en México ${ }^{6}$.

En 1945, Rivero Carvallo y Jiménez Romo presentaron un caso de persistencia del conducto arterioso en el Instituto Nacional de Cardiología, que fue operado exitosamente por Clemente Robles; posteriormente, Carlos Noble, en el Instituto Mexicano del Seguro Social, y Antonio Torres de Anda, en el Hospital Central Militar, realizaron con éxito dicha cirugía.

Clemente Robles inició la cirugía de la coartación aórtica y de la tetralogía de Fallot por la operación de Blalock.

Carlos Gómez del Campo y Jorge Meneses Hoyos, entre 1944 y 1946, realizaron por primera vez en el mundo coronariografías en el ser humano, en el Hospital Central Militar?.

En 1952, Héctor Pérez Redondo inició la cirugía de la estenosis mitral, de gran importancia social por ser la reumática la cardiopatía más importante entre nosotros ${ }^{8}$.

En 1944, en el Hospital Juárez de la Ciudad de México, Juan José Quesada realizó angiocardioneumografías por primera vez en México.

En el Hospital General de México, en 1949, Pablo Barroeta introdujo en México el empleo de prótesis valvulares artificiales de plástico (nailon, teflón y dacrón), impulsando un nuevo paso en la cirugía cardiaca.

Martín Maquívar fundó en 1954 la primera residencia para anestesiólogos en el Hospital General de México, y al año siguiente lo hizo en el Instituto $\mathrm{Na}$ cional de Cardiología.
En 1957, por iniciativa e impulso de Clemente Robles, se fundó la Asociación Mexicana de Cirugía Cardiovascular.

Héctor Pérez Redondo, en 1961, hizo la primera comisurotomía mitral a corazón abierto en el país.

En 1963 se llevó a cabo la introducción de las prótesis valvulares del corazón. En México, Patricio Benavides, el 19 de abril de ese año, puso la primera prótesis de Starr, y poco después J. Pliego colocó la primera en posición aórtica.

Refiere Quijano Pitman que Javier Palacios Macedo se había preparado para llevar a efecto el primer trasplante de corazón, pero que por orden presidencial fue cancelado, pues la legislación mexicana no permitía los trasplantes de órganos vitales e impares; el 21 de julio de 1988, Rubén Argüero Sánchez y su grupo, en el Centro Médico La Raza, del Instituto Mexicano del Seguro Social, realizaron con éxito el primer trasplante de corazón en México, y el 12 de septiembre de 1988 Palacios Macedo y su grupo efectuaron el segundo, en el Hospital de Cardiología del Centro Médico del Instituto Mexicano del Seguro Social ${ }^{9}$.

En 1946 se hizo la primera ligadura, con éxito total, del conducto arterial, llevada a cabo por Antonio Torres de Anda y Rubén Mingram Camargo, en el Hospital Central Militar ${ }^{10}$.

\section{Cirugía neumológica}

En cuanto a la neumología, en 1936 se inauguró el Sanatorio de Huipulco, en la Ciudad de México, con Donato G. Alarcón como director, Ismael Cosío Villegas como médico de esta institución y Alejandro Celis Salazar como radiólogo. Alejandro Celis inició en México la cirugía endotorácica, en el Hospital General de México, en el servicio de González Méndez, brillando en la unidad de neumología. En 1946, Celis obtuvo para México la prioridad mundial de un método personal para la angiocardiografía, trabajo que varios años después de haber sido publicado fue recogido en el libro editado en Europa para conmemorar los 100 años del descubrimiento de Roentgen como una de las contribuciones mundiales en la investigación radiológica ${ }^{11}$. Su técnica propia para introducir por la yugular externa una gruesa sonda, de calibre muy superior a las usadas en las venas del brazo, hasta la aurícula derecha, permitió inyectar velozmente una cantidad de medio de contraste sin dilución alguna, y obtener así imágenes mucho mejores, más nítidas y claras, con un contraste excelente, que las obtenidas con otras 
técnicas y vías de acceso; obtuvo esas imágenes con un modesto aparato de cien miliamperios ${ }^{12}$.

\section{Cirugía oftalmológica y otorrinolaringológica}

En el caso de la oftalmología, en cuanto a su enseñanza de posgrado, fue en 1947 cuando en el Hospital General de México Magín Puig Solanes organizó los cursos correspondientes, que fueron tomados posteriormente por las demás instituciones educativas.

Las enfermedades oculares se han estudiado sistemáticamente, como son los casos de la oncocercosis en el Hospital General de México, las afecciones vasculares en el Instituto Nacional de Cardiología, las alteraciones metabólicas, en especial la diabetes mellitus, así como la toxoplasmosis, en el Hospital Infantil de México y en el Hospital de Pediatría del Instituto Mexicano del Seguro Social, los tumores intraoculares en el Hospital General de México, la Asociación para Evitar la Ceguera en México, el Hospital Infantil de México, el Instituto Nacional de Pediatría y otros más, y tumores de la órbita en la Asociación para evitar la Ceguera en México, entre otros.

Médicos como Antonio Torres Estrada, Luis Sánchez Bulnes, Enrique Graue y Díaz González, Juan Heatley Green, Manuel de Rivas Cheriff, María Teresa Arroyo Nieto, Francisco Javier Padilla de Alba, Ruperto Méndez, Magín Puig Solanes, Anselmo Fonte Bárcena, David Gutiérrez Pérez, Arenas, y patólogos oculares como Sadí de Buen López de Heredia, Alfredo Gómez Leal y Gabriel González Almaraz, han dado fama a la oftalmología mexicana.

Los diversos hospitales oftalmológicos, como el Instituto de Oftalmología Fundación Conde de Valenciana, Nuestra Señora de la Luz y el Luis Sánchez Bulnes de la Asociación para Evitar la Ceguera en México, así como los servicios oftalmológicos de los hospitales públicos, han dado múltiples muestras de su quehacer científico.

En la otorrinolaringología se mencionan las figuras de Daniel Gurría Urgell y de Juan Andrade Pradillo, Juan Becerril Carmona, Cleofás Padilla, Samuel Inclán y Andrés Bustamante Gurría (a quien se debe la fundación del Instituto Nacional de Audiología en 1954).

La Sociedad Mexicana de Oftalmología, fundada en 1893, pasó a llamarse en 1920 Sociedad Mexicana de Oftalmología y Otorrinolaringología; se modificaron los estatutos, para que se alternaran los oftalmólogos y los otorrinolaringólogos como presidentes de la organización. En 1946 se separaron nuevamente las dos especialidades y la otorrinolaringología tuvo su sociedad propia, cuya mesa directiva estuvo conformada por Daniel Gurría Urgell como presidente, Ricardo Tapia Acuña como secretario, Mario González Ulloa como tesorero, Luis Vaquero Sánchez como secretario perpetuo y Ricardo Tapia Fernández como presidente honorario.

En el servicio de otorrinolaringología del Hospital General de México se practicaron las primeras broncoscopías directas, en 1932, y la primera anestesia endotraqueal, en $1933^{13}$.

\section{Cirugía ortopédica}

La ortopedia, como especialidad, se inició después de los años 1930 en el Hospital Juárez y en el Hospital General de México.

En octubre de 1935, en el Hospital Civil Ignacio de la Llave, de Orizaba, Veracruz, Ricardo Labardini Nava hizo una interesante observación de Pie de Madura, variedad blanca, en un campesino sifilítico, con anemia secundaria y albuminuria, en el que realizó con éxito la amputación de la pierna por el método de Francisco Montes de Oca, siendo este el primer caso de micetoma tratado quirúrgicamente en México ${ }^{14}$.

El mayor impulso a la ortopedia lo dio José Castro Villagrana en el Hospital Juárez, quien organizó el primer servicio de la especialidad, separando la ortopedia de la cirugía general al fundar la sala 17 para la atención de fracturas e infecciones óseas, para la que se nombró jefe a Guillermo Crity y como asociados a Alejandro Castanedo, Vicente Roqueñí, Pedro Rosas y García Figueroa.

En el Hospital General trabajaron como cirujanos generales Juan Farill, Eduardo Gómez Jáuregui y Alejandro Velasco Zimbrón.

En el Hospital Colonia de los Ferrocarriles Nacionales, Pablo Mendizábal impulsó la cirugía ortopédica.

En el Hospital Central Militar iniciaron la especialidad José A. Zapata y Rafael Moreno Valle.

En el Hospital Infantil de México, la ortopedia fue atendida por Juan Farill, Eduardo Gómez Jáuregui y Alejandro Velasco Zimbrón; Farill logró la fundación del Hospital Shriners para niños.

Velasco Zimbrón fundó el Hospital Germán Díaz Lombardo, el Hospital de Nuestra Señora de Guadalupe y la Clínica Primavera de Ortopedia (cerrada por falta de recursos económicos), todos ellos para enfermos del sistema músculo-esquelético, apoyados por patronatos privados. 
En 1944, el Instituto Mexicano del Seguro Social fundó el Hospital de Ortopedia y Traumatología, dirigido por José de Jesús Domínguez.

En 1948, a iniciativa de Luis Sierra Rojas, se fundaron los primeros dos bancos de huesos en nuestro país, el del Hospital Infantil de México y el del Hospital Central Militar.

La ortopedia y la traumatología mexicanas han estado presentes en el desarrollo nacional, en la creación de servicios especializados, como el Hospital Magdalena de las Salinas, el Hospital de Traumatología y Ortopedia de Lomas Verdes, y muchos más.

Trabajos hechos en México que han trascendido nuestras fronteras son los de José Ramón Aluja Deu, que abordó problemas de la circulación en el hueso, de tolerancia y resistencia de los materiales de implante, y de repercusión biológica del metilmetacrilato, entre otros más.

También se encuentran entre las investigaciones mexicanas la realizada sobre las alteraciones de la estructura ósea secundaria a la parálisis, por Felipe Gómez; la influencia de la estimulación eléctrica sobre las fracturas óseas de los conejos, de Salvador Beltrán; la fisiopatología y la etiopatogenia de la artrosis de la rodilla en animales, de Leonardo Zamudio; la investigación biomecánica del clavo de Colchero, centro medular con pernos, de Fernando Colchero R.; efectos en modelos fotoelásticos de las variaciones de la carga en la superficie acetabular, por modificaciones de coxa vara y coxa valga, de Raúl Sierra Campuzano; la instrumentación segmentaria de la columna vertebral, de Eduardo Luque R.; estudios sobre la fotoelasticidad, de Roberto Solares; lesiones de columna en perros, de Alfredo Iñárritu; estimulación mecánica como generadora de la osteogénesis, de Miguel Aguilar Casas, y muchas más ${ }^{15}$.

Un ortopedista mexicano olvidado es Alfonso Ortiz Tirado, médico del Hospital General de México, que fue un excelente y afamado tenor. Organizaba conciertos, en los que intervenía, y las ganancias obtenidas las donaba para los enfermos pobres de su servicio.

\section{Cirugía oncológica}

La oncología mexicana no se quedó atrás en su evolución. Horacio Zalce Torres, al haber tenido una formación de posgrado eminentemente quirúrgica en el Memorial Sloan-Kettering Cancer Center de Nueva York, decidió regresar a México y sumarse al equipo de especialistas del pabellón número 13 del Hospital General de México como responsable de cirugía, a principios de 1946, en donde se aplicó a la cirugía radical de los tumores localmente avanzados de cabeza y cuello seguida por procedimientos de reconstrucción quirúrgica, en colaboración con Alfonso Serrano, Fernando Ortiz Monasterio y Gustavo Barrera, quienes trabajaban en lo que se conoció como equipo móvil, por su colaboración con diferentes servicios del hospital. Zalce hacía resecciones amplias del tumor primario con disecciones ganglionares radicales en continuidad. Basándose en su experiencia planteó la importancia del criterio oncológico en el diagnóstico y el tratamiento del cáncer, haciendo énfasis en los riesgos de los errores quirúrgicos agravados por la mala preparación de los cirujanos sin especialización, insistiendo reiteradamente en la necesidad de organizar la enseñanza de la oncología quirúrgica como asignatura obligatoria desde la educación de pregrado.

En el Hospital Central Militar, el patólogo Luis Benítez Soto dio a conocer el primer caso observado en México de la enfermedad de Brill-Symmers o linfopatía gigantomolecular ${ }^{16}$.

Ortiz Monasterio menciona que de esta generación también debe destacarse la persona de José Manuel Velasco Arce, reconocido cirujano que dedicó su atención al cáncer de mama; en ese entonces, las operaciones más frecuentes eran la mastectomía radical y la mastectomía superradical, que requerían horas de trabajo delicado, y que dejaban secuelas graves como el linfedema del brazo homolateral. La actividad de Velasco Arce como maestro fue notable.

En 1946 se decretó la fundación del Instituto Nacional de Cancerología, que ha seguido fructificando para bien de la humanidad.

\section{Cirugía plástica}

Durante la Primera Guerra Mundial, la cirugía plástica se inició como especialidad quirúrgica cuando las mutilaciones, principalmente faciales, atrajeron la atención de numerosos cirujanos con formación diversa, quienes intentaban restaurar las pérdidas y tratar de devolver el aspecto normal a los soldados.

En la cirugía plástica mexicana destacó Mario González Ulloa. Más tarde lo hicieron Alfonso Serrano en el Hospital General de México y Óscar Ulloa Grégori en el Hospital Universitario de Monterrey.

\section{Analgesia y anestesia}

Hacia el 10 de junio de 1933 apareció el primer número de la Revista Mexicana de Cirugía, Ginecología 
y Cáncer, cuyo fundador y director fue Conrado Zuckermann ${ }^{17}$. El mismo Zuckermann introdujo la anestesia intravenosa con pentotal sódico, dando cuenta de los resultados obtenidos en enero de $1938^{18}$.

El dolor ha sido un problema al que se han enfrentado los pacientes con cáncer avanzado o terminal; en este campo, tanto Horacio Zalce como Guillermo Montaño Islas promovieron la formación de una clínica del dolor, siendo el pionero en este campo Vicente García Olivera ${ }^{19}$.

En 1943, en el Hospital General de México, Jorge Terrazas Molinar llevó a cabo la primera anestesia endotraqueal ${ }^{20}$.

Ese mismo año, Miguel López Esnaurrizar presentó en la Academia Mexicana de Cirugía su estudio Algias abdominales esplácnicas, que demostró por primera vez en la historia de la medicina la posibilidad de suprimir todo dolor visceral, aun por cáncer, por medio del bloqueo esplácnico con novocaína, seguido de alcohol ${ }^{21}$.

\section{Transfusión sanguínea}

Un adelanto más en la cirugía mexicana fue la publicación en 1942 del primer Manual de transfusión sanguínea hecho en América Latina, debido a Alfonso Martínez Álvarez.

A fines de 1942, en el mes de noviembre, se realizó el Primer Congreso Nacional de Transfusión Sanguínea, organizado por Eduardo Uribe Guerola; este evento tuvo lugar dentro de la $V$ Asamblea Nacional de Cirujanos, en el Hospital Juárez.

En el Hospital Español, el 8 de febrero de 1950 se realizó una proeza para esas fechas, que fue el primer caso en México de una exsanguinotransfusión total, por leucemia linfoide, en una señora de 28 años de edad, durando la operación 7 horas y media, transfundiéndose 15 litros y extrayéndose 12; en ella intervinieron Eduardo Uribe Guerola, Rolando Medina Aguilar y Alfonso Vélez Orozco22.

\section{Ginecología y obstetricia}

Luis Carrillo Azcárate, en mayo de 1939, publicó su Memoria sobre la adenopatía inguinal y lesiones del cuello del útero, en la que por primera vez en México se señaló la relación entre la adenitis inguinal con las lesiones del cuello de la matriz, especialmente cáncer e inflamaciones chancrosas ${ }^{23}$.

En 1944, durante la VII Asamblea Nacional de Cirujanos, en la que estaba programada una sección de ginecología y otra de obstetricia, Alejandro Otero, ginecólogo español exiliado en México, propuso que las dos secciones sesionaran conjuntamente, siendo exitosa su idea. Entonces se integró una comisión encargada de iniciar los trabajos conducentes a formar una asociación ginecológica y obstétrica, la que quedó formada por Alfonso Álvarez Bravo, Alcibíades Marván, Luis Gómez Daza, Carlos D. Guerrero y David Fragoso Lizalde, fructificando en la fundación de la Asociación Mexicana de Ginecología y Obstetricia.

La enseñanza de la gineco-obstetricia cambió, siendo el Hospital Español el germen de la inquietud por formar especialistas en el área ${ }^{24}$.

\section{Cirugía urológica}

Los temas principales de la urología entre 1930 y 1950 fueron la cirugía prostática, la tuberculosis genitourinaria, las infecciones urinarias, las iatrogenias del aparato urinario femenino, el tratamiento de las estenosis de la uretra y la curación de las enfermedades producidas por contacto sexual, para aplicar más tarde los procedimientos modernos en la prevención y el tratamiento de estos y otros padecimientos.

La farmacéutica y la electrónica han revolucionado constantemente la práctica de la medicina, y la urología no ha sido la excepción. Estuvieron de moda la derivación urinaria, sus técnicas y complicaciones; se fomentó ampliamente la urología pediátrica, el reflujo vesicoureteral, la extrofia de la vejiga, el hipospadias y la criptorquidia. La urodinamia fue desarrollándose hasta desempeñar un papel diagnóstico adecuado. El trasplante renal y la hemodiálisis son procedimientos frecuentes en la actualidad. El tratamiento de la incontinencia urinaria y la implantación de prótesis ocupan gran parte del quehacer urológico. El tratamiento de la litiasis renal, ureteral y vesical ha cambiado radicalmente. Ha habido un progreso constante en la fabricación de equipos, instrumentos endoscópicos y sondas, y la imagenología, la medicina nuclear y la andrología son la base de los conocimientos y tratamientos actuales.

Urólogos mexicanos de renombre han sido Aquilino Villanueva, Manuel Pesqueira, Manuel Lezama, Ángel Quevedo, Aniceto Orantes, Oscar Chapa, Arturo Lara Pivas, Javier Lomelín, Carlos Pres, Manuel Ballesteros y Raúl López Engelking, entre otros muchos más. En 1946, Aquilino Villanueva fundó los cursos de urología para médicos graduados, entre los que figuraron como alumnos Oswaldo Arias Capetillo, Ricardo López Jara, Adolfo Isla Cosío, González de Alba, Guani 
Lira, Juan José González Moreno, José de la Torre, Santiago Blanco y Humberto Guzmán Páez, quienes se encargaron de formar a nuevos especialistas.

El mismo Villanueva fundó la residencia en urología, siendo los primeros residentes Manuel Alcaraz, Miguel Vértiz, Arturo Díaz Flores, Juan Maldonado, David Jiménez, Rodolfo Pérez Rodríguez, Miguel Virgen y Federico Ortiz Quesada.

A partir de 1945 ingresaron al pabellón 5 del Hospital General de México nuevos urólogos: Jesús Álvarez lerena, Jaime Woolrich Domínguez, Xavier Ibarra, Edmundo Alpuche, Salvador Salinas, Moisés Lisker, Jorge Elías Dib, Ignacio Purpon y Carlos García Irigoyen.

Javier Longoria, otro cirujano distinguido, sucedió en la jefatura del pabellón 5 a Aquilino Villanueva.

El servicio de urología del Hospital Juárez fue fundado por Carlos Aguirre, quien más tarde llegó a ser director de dicho hospital. Fue un excelente cirujano, rápido, elegante, siendo sus colaboradores Eduardo Castro de la Parra, Petroni, Reyes Tamayo, Jesús Varela Rico, H. Compean, J. Saulny, A. Morán, Ángel Orozco Bravo y Francisco Valdés la Vallina.

En el Hospital Central Militar han destacado, entre otros, Luis Rivero Borrell, Gilberto F. Lozano García, Rodolfo Vera Barriguete y Leonides Andrew Almazán, Miguel Cervantes Olvera y Elías Zonana Farca. Rivero Borrell dio a conocer, en 1935, un procedimiento original para puncionar la vejiga ${ }^{25}$.

Desde los años 1930, la cirugía genitourinaria ha sido perfeccionada; la corrección de hipospadias, epispadias, extrofia vesical y estados intersexuales han sido algunos de los padecimientos tratados.

La cirugía prostática ha sido mejorada debido a la cirugía endoscópica transuretral. La nefrostomía y la cistostomía fueron sustituidas por la intubación intrapélvica renal o vesical por vía percutánea, translumbar o hipogástrica.

La ureterosigmoidostomía, el conducto ileal, las enterocistoplastías y las sustituciones ureterales por segmentos de íleo perdieron adeptos y se puso de moda la vejiga continente de Koch.

La litotomía se ha convertido en un procedimiento frecuente, usándose el litotritor ${ }^{26}$.

\section{Cirugía gastroenterológica}

En el campo de la gastroenterología, los médicos que se habían dedicado con más atención a ella fundaron la Asociación Mexicana de Gastroenterología con fecha 16 de julio de 1935, y su órgano oficial, la Revista Mexicana de Gastroenterología, apareció en septiembre del mismo año. Los socios fundadores fueron Alfonso Acevedo Olvera, Francisco Ávila, Francisco Bassols, Rafael Blanc, Armando Bustos Naude, Carlos Coqui, Alberto Cancino, Jorge Flores Espinosa, Leónides Guadarrama, Soledad Luna de Gamboa, Enrique Madrigal, Raúl Meurine, Ignacio Millán, Guillermo Montaño, Pablo Ortega, Mario Quiñones Huertero y Alfonso Rojas.

Como representante de la gastroenterología mexicana en aquel momento resplandeció Abraham Ayala González, quien hizo la primera gastrectomía por cáncer gástrico en 1943, y en 1945 practicó la vaguectomía para el tratamiento de la úlcera duodenal, primero por vía torácica y luego abdominal; el seguimiento cuidadoso de los enfermos le llevó a la conclusión de que no siempre resolvía la úlcera duodenal y podía producir iatrogenias, como retención gástrica, síndrome de vaciamiento rápido, y alteraciones de la función hepática y pancreática, por lo que abandonó esta técnica. Para el tratamiento quirúrgico de las úlceras gástricas o duodenales prefirió la gastrectomía subtotal, con gastroyeyunoanastomosis tipo Polya, que daba mejores resultados.

Ayala González describió, junto con Leónides Guadarrama, la ileítis regional en 1934, aunque recordaba haber visto casos de esta patología desde 1932.

En 1936, como trabajo de ingreso a la Academia Nacional de Medicina, Ayala presentó sus Estudios sobre la gastroscopía en México, que inició con el aparato rígido de Elsner en 1926 y prosiguió con el semiflexible de Schindler. En enero de 1939 hizo la primera peritoneoscopía con el aparato de Ruddock.

Entre los primeros sitios donde se practicó en forma moderna la gastroenterología se encuentra el pabellón 24 del Hospital General de México, inaugurado el 23 de junio de 1937. Constaba de dos pisos que alojaban 80 camas. Tenía un quirófano, en el extremo poniente, dotado de todos los elementos para llevar a cabo las cirugías del aparato digestivo; en sus paredes, cubiertas de anaqueles con puertas de cristal, estaban los instrumentos especializados: pinzas de Partipilo y de Abadie, para hacer anastomosis asépticas intestinales; pinzas de Payr grandes y chicas, para hacer las gastrectomías; pinzas de Wangesteen, para hacer la gastroyeyunoanastomosis aséptica; botones de Murphy; pinzas de Satinsky y finas de bulldog, para hacer anastomosis vasculares, etc. Tenía una mesa de operaciones con el cojín especial para la raquia Lemmon, que podía quitarse cuando no era necesario; una lámpara central con muchos espejos, que proyectaba una excelente luz 
sin sombras sobre el campo operatorio; lámparas accesorias de pie; aspiradores eléctricos; y aparatos de anestesia por inhalación. A su entrada estaba la sala de lavabos, de la cual se accedía directamente al quirófano y a la que no se entraba si no se tenía ya la ropa apropiada. Tenía también una sala de rayos $X$ con su correspondiente cuarto oscuro, a cargo de Soledad Luna de Gamboa y de Enrique Gamboa Luna. En la planta alta estaba el laboratorio, a cargo de Roberto Alfaro Trejo.

También en la planta alta, en el extremo poniente, estaba la sala de endoscopía en la que los lunes, miércoles y viernes se hacían endoscopías altas, esofagoscopías y gastroscopías, y martes, jueves y sábado se hacían endoscopías bajas, de recto y sigmoidoscopías, estas últimas a cargo de Alberto Robles Díaz, al principio, y después de Octavio Avendaño Espinosa. Había también una tizanería, en la que se preparaban alimentos especiales o se calentaban los suministrados por la cocina central del hospital27.

\section{Revistas, reuniones y exposiciones}

En agosto de 1933 se publicó el primer número de la revista Cirugía y Cirujanos, órgano de difusión de la Academia Mexicana de Cirugía, dirigida en ese entonces por el Dr. José Aguilar Álvarez.

Dentro de otras aportaciones de Aguilar Álvarez al quehacer quirúrgico en México está el haber fundado en 1943, en el Hospital Español, el Servicio de Anestesiología. Debido a iniciativas de él se crearon el Laboratorio de Ginecología Endocrina, primero en el país, el Departamento de Broncoesofagología y el Servicio de Cancerología ${ }^{28}$.

Por primera vez en México, el Dr. Luis Carrillo Azcárate dio a conocer su trabajo sobre el tratamiento de las cervicitis como método preventivo del cáncer del cuello uterino.

Hacia el 10 de noviembre de 1933, el Dr. José Torres Torija dio a conocer su estudio La documentación hospitalaria, asunto tratado particularmente desde el punto de vista quirúrgico y que se refiere a la necesidad de unificar y organizar, en forma vasta y permanente, toda la información adecuada relativa a los operados.

En noviembre de 1934 se efectuó la Primera Asamblea Nacional de Cirujanos, en el Hospital Juárez, cuyo presidente fue José Castro Villagrana ${ }^{29}$. Esta importante reunión quirúrgica se sigue llevando a cabo, con la participación de numerosos médicos mexicanos y del extranjero, intercambiando conocimientos e ideas.

La aparición del órgano oficial del Instituto Asambleas Nacionales de Cirujanos, la revista Anales de Cirugía, aconteció en el mes de octubre de $1949^{30}$.

De los días 3 al 10 de enero de 1936 se realizó el Primer Congreso Mexicano de Cirugía, bajo la presidencia de Gonzalo Castañeda, convocado y organizado por la Academia Mexicana de Cirugía ${ }^{31}$.

En 1939, el 20 de marzo, quedó establecido en la Ciudad de México el Capítulo Mexicano del Colegio Internacional de Cirujanos ${ }^{32}$.

Uno de los pilares básicos de un cirujano es el conocimiento detallado de la anatomía. En 1946 se presentó la primera exposición, en la Escuela Nacional de Medicina, del entonces novísimo sistema de enseñanza de las disecciones de anatomía topográfica, que comprendía la plastiescultura anatómica y la disectocromía, inventadas respectivamente por los prosectores Manuel Flores Rosas y José Negrete Herrera $^{33}$.

En 1949 apareció el primer ejemplar de la revista Cirugía y Medicina, órgano oficial del Hospital y de la Sociedad Médica de la Cruz Roja Mexicana, cuyo director en ese entonces fue Luis Andrés Lagarde y su director honorario fue Mario Valles ${ }^{34}$.

\section{Odontología}

Desde la creación de la Escuela Nacional de Odontología en 1913 se hicieron intentos de organización gremial que dieron como resultado, en 1942, la creación de la Organización Dental Mexicana, que reunió a los principales dentistas de esa época, entre los que se encontraban Félix del Paso, Yuri Kutler, Enrique Aguilar, Manuel Faril, Fermín Reygadas, Samuel Fastlicht, Roberto Rojo de la Vega, Martínez Lugo, Palacio Gómez, Francisco Miranda, Ignacio Reynoso, Sánchez Cordero y Román Lascurain, entre otros.

Dentro del campo de la odontología, las subespecialidades se iniciaron en la década de 1930, principalmente con profesionales formados en el extranjero, creándose más tarde las asociaciones de cirugía, ortodoncia, odontopediatría, parodoncia, prótesis y endodoncia, entre otras más ${ }^{35}$.

\section{Conclusiones}

Las especialidades médicas y médico-quirúrgicas se han transformado desde su aparición. En 1893, la oftalmología ya se había consolidado como una 
especialidad, pues en la Escuela Nacional de Medicina de México se abrieron los cursos de perfeccionamiento médico para las enfermedades oculares, mentales y obstétricas, pero no fue hasta la década de 1930 y en adelante que los médicos cirujanos decidieron emprender la consolidación de su preparación profesional dedicándose a alguna especialidad, al inicio de manera tutorial y después de acuerdo con los planes de estudio universitarios.

Así, dentro de su progreso, han formado sociedades médicas, han editado revistas especializadas y, ya en la década de 1970, iniciaron su andadura los Consejos de Certificación, lo que ha mejorado sustancialmente la práctica de la cirugía.

\section{Apéndice 1}

Sociedades y asociaciones médicas fundadas después de 1933 (vigentes en 1987) ${ }^{36}$

1934: Sociedad de Anestesistas de México (Sociedad Mexicana de Anestesiología, desde 1948).

1935: Sociedad Mexicana de Cardiología

1935: Asociación Mexicana de Gastroenterología

1935: Sociedad Mexicana de Medicina Interna

1936: Sociedad Mexicana de Dermatología

1936: Sociedad Mexicana de Urología

1939: Sociedad Mexicana de Estudios sobre Tuberculosis y Enfermedades del Aparato Respiratorio (Sociedad Mexicana de Neumología y Cirugía del Tórax, desde 1961).

1942: Sociedad Mexicana de Radiología y Fisioterapia (Sociedad Mexicana de Radiología, desde 1951).

1944: Sociedad Mexicana de Ortopedia

1945: Asociación Mexicana de Ginecología y Obstetricia

1946: Sociedad Mexicana de Otorrinolaringología y Broncoesofagología

1948: Asociación Mexicana de Cirujanos Plásticos

1951: Sociedad Mexicana de Estudios Oncológicos

1952: Academia Mexicana de Dermatología

1953: Asociación Mexicana de Hospitales

1954: Asociación Mexicana de Patólogos

1954: Sociedad Mexicana de Cirugía Neurológica

1957: Asociación Mexicana de Cirugía Cardiovascular

1960: Federación Mexicana de Asociaciones de Ginecología y Obstetricia

1960: Sociedad Mexicana de Reumatología
1966: Sociedad Mexicana de Medicina Física y Rehabilitación

1967: Sociedad Mexicana de Nefrología

1968: Asociación Mexicana de Ortopedia y Traumatología

1969: Asociación Mexicana de Cirugía Bucal y Maxilofacial

1970: Asociación Mexicana de Patología Clínica

1972: Asociación Mexicana de Infectología

1972: Sociedad Mexicana de Inmunología

1973: Asociación Mexicana de Terapia Intensiva

1974: Federación Mexicana de Sociedades de Radiología

1974: Colegio Mexicano de Urología

1976: Academia Mexicana de Neurología

1979: Asociación Mexicana de Glaucoma

1979: Asociación Mexicana de Retina

1980: Asociación Mexicana de Cirugía de Mano

1984: Sociedad Mexicana de Ortopedia Pediátrica

1984: Sociedad de Labio y Paladar Hendido y Anomalías Craneofaciales.

1984: Sociedad de Quemaduras

1984: Colegio Nacional de Cirujanos Dentistas

A estas organizaciones académicas han continuado muchas más, de acuerdo con el desarrollo imparable de la medicina y de la cirugía.

\section{Apéndice 2}

Revistas médicas (aparecidas a partir de 1933 y vigentes en 1987) ${ }^{37}$

1933: Cirugía y Cirujanos

1935: Revista de Gastroenterología de México

1935: Prensa Médica Mexicana

1937: Archivos de Psiquiatría de México

1939: Neumología y Cirugía del Tórax (Revista Mexicana de Tuberculosis y Enfermedades del Aparato Respiratorio, hasta 1962)

1943: Boletín Médico del Hospital Infantil de México

1943: Revista Mexicana de Urología

1944: Archivos del Instituto Nacional de Cardiología de México

1944: Revista Mexicana de Patología Clínica

1947: Anales de la Sociedad Mexicana de Oftalmología (fundada en 1898 como Anales de la Sociedad Oftalmológica Mexicana y actualmente Revista de la Sociedad Mexicana de Oftalmología)

1947: Revista Mexicana de Radiología

1948: Revista de Investigación Clínica

1948: Revista de Sanidad Militar 
1949: Anales de la Sociedad Mexicana de Otorrinolaringología

1952: Revista Mexicana del IMSS

1952: Revista Mexicana de Anestesiología

1952: Higiene

1953: Alergia

1954: Revista del Instituto Nacional de Cancerología

1955: Anales de Rehabilitación

1956: Dermatología

1958: Revista Mexicana de Microbiología

1959: Revista de Neurología, Neurocirugía y Psiquiatría

1959: Salud Pública de México

1965: Cuadernos de Psicoanálisis

1968: Psiquiatría

1970: Archivos de Investigación Médica, IMSS

1970: Patología

1973: Revista Mexicana de Angiología

1977: Salud Mental

1980: Acta Pediátrica de México

1980: Cirujano General

1980: Infectología

1980: Nefrología Mexicana

1981: Cuadernos de Nutrición

1983: Revista Médica del Distrito Federal

1984: Revista de la Asociación de Medicina Crítica y Terapia Intensiva

1985: Revista de la Asociación de Medicina Interna de México

1986: Medicine (México)

1986: Revista Mexicana de Ortopedia y Traumatología

1986: Revista Mexicana de Reumatología

1986: Revista de Perinatología

\section{Conflicto de intereses}

Los autores declaran que este artículo no contiene conflicto de intereses, ni recibió financiamiento alguno.

\section{Bibliografía}

1. Campuzano FM. Cirugía general. En: Soberón G, Kumate J, Laguna J, compiladores. La salud en México: testimonios 1988. Especialidades médicas en México, tomo II. México: Secretaría de Salud, Instituto Nacional de Salud Pública, El Colegio Nacional, Fondo de Cultura Económica; 1989. p. 71-3

2. Ortiz MG. La escuela quirúrgica mexicana. Semblanza de Gonzalo Castañeda, Darío Fernández y Aquilino Villanueva. En: Uribe Elías R, coordinador. El pensamiento médico contemporáneo. 2. ${ }^{a}$ ed. México: Sociedad Mexicana de Historia y Filosofía de la Medicina, Universidad Autónoma de Aguascalientes; 2009. p. 351-64.

3. Alcántara HJ. Compendio de cronología quirúrgica mexicana. México: Academia Mexicana de Cirugía; 1951. p. 154.
4. Velasco SM. Neurocirugía. En: Soberón G, Kumate J, Laguna J, compiladores. La salud en México: testimonios 1988. Especialidades médicas en México, tomo II. México: Secretaría de Salud, Instituto Nacional de Salud Pública, El Colegio Nacional, Fondo de Cultura Económica; 1989. p. $122-50$.

5. Quijano NM. Vanguardia y trabajo que abren nuevos caminos. Semblanzas de Clemente Robles y de Luis Sánchez Medal. En: Uribe Elías R, coordinador. El pensamiento médico contemporáneo. 2. ${ }^{a}$ ed. México: Sociedad Mexicana de Historia y Filosofía de la Medicina, Universidad Autónoma de Aguascalientes; 2009. p. 97-108.

6. Quijano PF. Primicias médicas potosinas y varia. San Luis Potosí: Universidad Autónoma de San Luis Potosí; 1992. p. 79-82.

7. Ídem. p. 177-9.

8. Neri CR. Epidemiología de las enfermedades del corazón en México. Gac Med Mex. 1959; 89:183-97.

9. Quijano PF. La cirugía cardiaca en México. México: Universidad Nacional Autónoma de México, Facultad de Medicina, Departamento de Historia y Filosofía de la Medicina, Programa Universitario de Investigación en Salud (PUIS), Fundación Miguel Alemán A.C.; 1996. p. 56-80.

10. Alcántara HJ, op. cit. p. 198.

11. Rivero SO. La escuela neumológica mexicana. Los pilares de la neumología en México. Semblanzas de Donato G. Alarcón, Ismael Cosío Villegas y Alejandro Celis Salazar. En: Uribe Elías R, coordinador. El pensamiento médico contemporáneo. 2. ${ }^{\text {a } ~ e d . ~ M e ́ x i c o: ~ S o c i e d a d ~ M e x i c a n a ~ d e ~}$ Historia y Filosofía de la Medicina, Universidad Autónoma de Aguascalientes; 2009. p. 187-97.

12. Quijano PF, op. cit. p. 41.

13. Tapia AR. Otorrinolaringología. En: Soberón G, Kumate J, Laguna J, compiladores. La salud en México: testimonios 1988. Especialidades Médicas en México, tomo II. México: Secretaría de Salud, Instituto Nacional de Salud Pública, El Colegio Nacional, Fondo de Cultura Económica; 1989. p. 181-6.

14. Alcántara HJ, op. cit. p. 161-2.

15. Sierra RL. Ortopedia y traumatología. En: Soberón G, Kumate J, Laguna J, compiladores. La salud en México: testimonios 1988. Especialidades médicas en México, tomo II. México: Secretaría de Salud, Instituto Nacional de Salud Pública, El Colegio Nacional, Fondo de Cultura Económica; 1989. p. 169-75.

16. Alcántara HJ, op. cit. p. 209.

17. Ídem, p. 150.

18. Ídem, p. 175

19. García SM. Una lucha que abre un camino de conocimiento y de respuesta social. En: Uribe Elías R, coordinador. El pensamiento médico contemporáneo. 2. ${ }^{a}$ ed. México: Sociedad Mexicana de Historia y Filosofía de la Medicina, Universidad Autónoma de Aguascalientes; 2009. p. 225-37.

20. Alcántara HJ, op. cit. p. 189.

21. Ídem, p. 192.

22. Ídem, p. 213.

23. Ídem, p. 180.

24. Álvarez BA. Ginecobstetricia. En: Soberón G, Kumate J, Laguna J, compiladores. La salud en México: testimonios 1988. Especialidades médicas en México, tomo II. México: Secretaría de Salud, Instituto Nacional de Salud Pública, El Colegio Nacional, Fondo de Cultura Económica; 1989. p. 112-4.

25. Alcántara HJ, op. cit. p. 161.

26. López ER. Urología. En: Soberón G, Kumate J, Laguna J, compiladores. La salud en México: testimonios 1988. Especialidades médicas en México, tomo II. México: Secretaría de Salud, Instituto Nacional de Salud Pública, El Colegio Nacional, Fondo de Cultura Económica; 1989. p. 196-211.

27. Anzures LME. Una escuela que consolida una institución. Abraham Ayala González y la escuela de gastroenterología. En: Uribe Elías R, coordinador. El pensamiento médico contemporáneo. 2. ${ }^{a}$ ed. México: Sociedad Mexicana de Historia y Filosofía de la Medicina, Universidad Autónoma de Aguascalientes; 2009. p. 275-90.

28. Alcántara HJ, op. cit. p. 188.

29. Ídem, p. 156.

30. Ídem, p. 210.

31. Ídem, p. 167.

32. Ídem, p. 180.

33. Ídem, p. 198

34. Ídem, p. 209.

35. Sánchez TJ. Estomatología. En: Soberón G, Kumate J, Laguna J, compiladores. La salud en México: testimonios 1988. Especialidades médicas en México, tomo II. México: Secretaría de Salud, Instituto Nacional de Salud Pública, El Colegio Nacional, Fondo de Cultura Económica; 1989. p. 94-101.

36. Soberón G, Kumate J, Laguna J, compiladores. La salud en México: testimonios 1988. Especialidades médicas en México, tomo II. México: Secretaría de Salud, Instituto Nacional de Salud Pública, El Colegio Nacional, Fondo de Cultura Económica; 1989. p. 297-300.

37. Ídem, p. 301-4. 